\title{
ANL/CHM/PE-87054
}

\section{WHY IN SITU, REAL-TIME CHARACTERIZATION OF THIN FILM GROWTH PROCESSES?}

\author{
O. Auciello ${ }^{1}$ and A. R. Krauss ${ }^{2}$
}

$\overline{{ }^{1} \text { Materials Science and }}$ Chemistry Divisions, Argonne National Laboratory, Argonne, Il 60439 ${ }_{2} \mathrm{MCNC}$, Electronic Technology Division, Research Triangle Park, NC 27709

\section{Editorial}

\author{
"In Situ, Real-Time Characterization of Thin Film \\ Growth Processes," O. Auciello and A. R. Krauss, \\ Guest Editors, MRS Bulletin, XX(5), May 1995
}

\section{DISCLAIMER}

This report was prepared as an account of work sponsored by an agency of the United States Government. Neither the United States Government nor any agency thereof, nor any of their employees, makes any warranty, express or implied, or assumes any legal liability or responsibility for the accuracy, completeness, or usefulness of any information, apparatus, product, or process disclosed, or represents that its use would not infringe privately owned rights. Reference herein to any specific commercial product, process, or service by trade name, trademark, manufacturer, or otherwise does not necessarily constitute or imply its endorsement, recommendation, or favoring by the United States Government or any agency thereof. The views and opinions of authors expressed herein do not necessarily state or reflect those of the United States Government or any agency thereof.

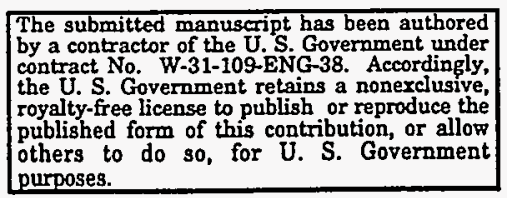

*Work supported by the U.S. Department of Energy, BES-Materials Sciences, under Contract W-31-109-ENG-38. 


\section{DISCLAIMER}

Portions of this document may be illegible in electronic image products. Images are produced from the best available original document. 


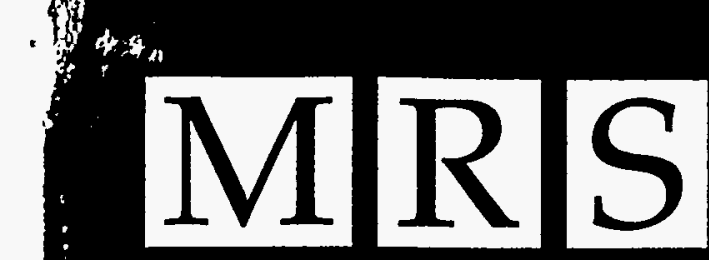

\section{In Situ, Real-Time Characterization of Thin-Film Growth Processes}
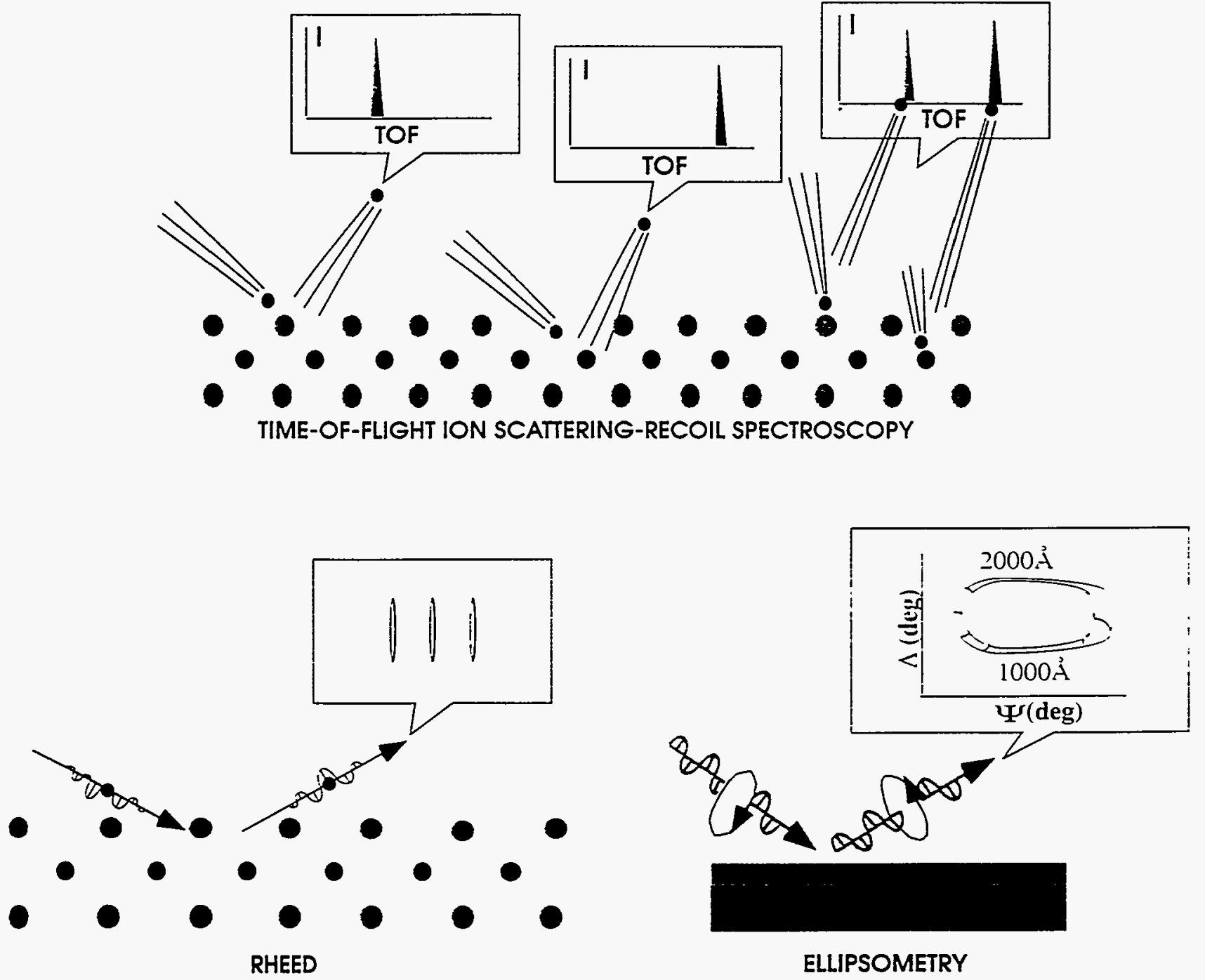


\section{Why In Situ, Real-Time}

Characterization of Thin-Film Growth Processes?

\section{Orlando Auciello and Alan R. Krauss, Guest Editors}

It is anticipated that a new generation of advanced electronic and optical devices will involve the synthesis of diverse materials in single or multielement thin-film form, or in layered heterostructures. These devices will most likely involve diverse materials such as hightemperature superconductors, ferroelectric, electrooptic, and optical materials; diamond; nitrides; semiconductors; insulators; and metals ${ }^{\prime}$ in the form of ultrathin lavers $w$ ith sharp interfaces in which the laver thickness mav reach atomic dimensions. Therefore, it becomes increasingly important to be able to monitor the deposition process in situ and in real time, particularly for complex multicomponent oxides or nitrides, in which the production of the desired phase is a highly sensitive function of the growth conditions, of ten requiring relatively high-pressure oxygen or nitrogen environments up to several hundrect mTorr, and in some cases, several Torr.' Consequently, the growth environment for many of these materials is incompatible with conventional surface-analytic methods, which are trpically restricted to high- or ultrahigh-vacuum conditions. New deposition and analytical methods, or adaptation of those alreadv established. will be required.

Since thin-tilm growth occurs at the surface, the analytical methods should be highly surface-specific, although subsurface diffusion and themical processes also affect film properties. Sampling depth and ambient-gas compatibility are key factors which must be considered when choosing in situ probes of thinfilm growth phenomena. In most cases, the sampling depth depends on the mean range of the exit species (ion, photon, or electron) in the sample. Techniques such as low energy electron diffraction (LEED), Auger electron spectroscopy (AES), and ultraviolet (UPS) and $x$-ray photoelectron spectroscopies (XPS) detect $100-2,000 \mathrm{eV}$ electrons which have a typical range of $\sim 5-40 \AA$ in solids. However, electrons also undergo significant gas-phase scattering which degrades the energy information and limits their analytical usefulness to high and ultrahigh-vacuum environments. Reflection high energy electron diffraction (RHEED) emplovs higher energy electrons $(-20 \mathrm{keV})$ and may be used at pressures up to $10^{-6}-10^{-5}$ Torr. Low-energy (several $\mathrm{keV}$ ) ion-beam techniques such as ion scattering spectroscopv (ISS) and direct recoil spectroscopies (DRS) provite perhaps the most suriace-specific information of any anaiysis method, but because they are relatively insensitive to multiple-scattering effects, the quality of the information is not seriously degraded by passage through a region of modest ambient-gas pressure. Methods which detect higher energy ( $\mathrm{MeV}$ ) ions such as Rutherford backscattering spectroscopy (RBS) and elastic recoil detection (ERD) are even less subject to gas-phase scattering, and mav be used at pressures up to 1 atm.: However the sampling depth increases to
$0.5-2 \mu \mathrm{m}$. A similar sampling depth is obtained for methods which detect $\mathrm{r}$-rav photons, unless they employ a grazing exit angle to limit the depth of signal origin or grazing incidence to limit the probe depth. Finallv, methods which employ visible light such as ellipsometry and interference spectroscopy are not surface-specific, but are userul probes of thin-film growth processes because thev determine macroscopic properties such as film thickness, roughness, index of refraction, and growth rate. Methods which detect $x$-ray or visible photons can typically be used at almost any pressure.

The techniques that are discussed in this issue of the MRS Bulletin (see schematics in Figure 1) have been chosen because they may be used for in situ. real-time analysis of film-growth phenomena in vacuum and in the presence of ambient gases resulting either from the deposition process or as a requirement for the production of the desired chemical phase. A second criterion for inclusion is that the instrumentation be sufficiently compact and inexpensive to permit use as a dedicated tool in a thinfilm deposition system.

The article by A.R. Krauss, O. Auciello, and J.A. Schultz describes the development and application of low-energy (5-15 keV) time-of-flight ion scattering and recoil spectroscopy (TOF-ISARS) methods, ${ }^{3}$ which can provide a remarkably wide range of information on surface composition, atomic structure of the first few monolavers, lattice-defect density, trace-element analysis, phonon characteristics, and in some cases, the chemical phase of the growing film in thin-film deposition environments.

The article by E.A. Irene and J.A Woollam describes spectrometric ellipsometry (SE), a well-established technique that can be used for in situ. real-time analysis of grow th processes.: This method has been extensively used in analysis of semiconductors, and most recently has been applied to study complex high-temperature surerconductors and ferroelectric films as examples of complex multicomponent materials. This technique provides information on surtace roughness, intertace sharpness, and defect density, for example, but interpretation of the data is only possible using a parametric model which requires additional information such as composition. lattice structure, and interface characteristics that can be provided by various techniques, including TOF-ISARS.

The article by C.D. Zuiker, D.M Gruen, and A.R. Krauss examines the use of optical interference spectroscopy: 


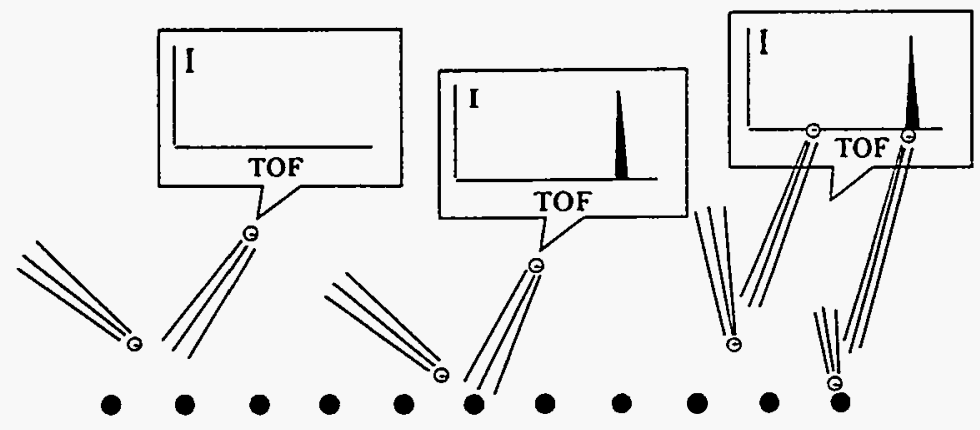

TIME-OF-FLIGHT ION SCATTERIYG-RECOIL SPECTROSCOPY

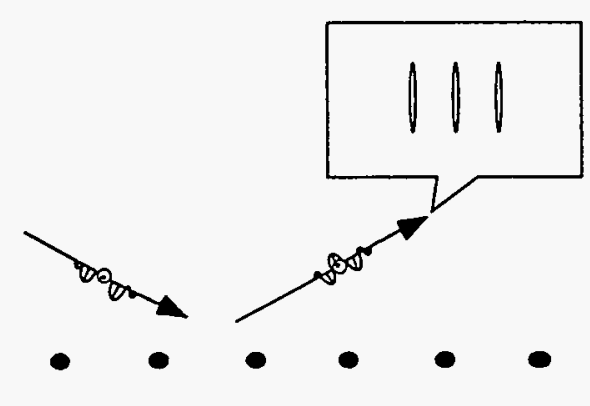

RHEED

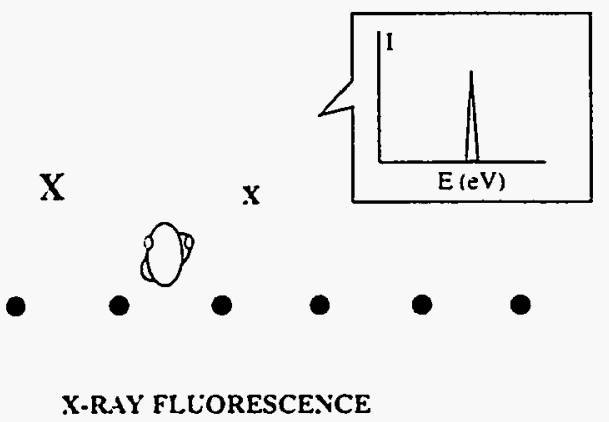

X-RAY FLLORESCE.YCE

Figure 1. Schematics showing the principle of the in situ, real-time characterization techniques discussed in this issue.

as an in situ means of measuring filmgrowth rate and surface roughness on the micron scale. This method has the virtue of simple setup, low cost, and the ability to provide some of the information required for the interpretation of ellipsometric data.

The article by I. Bozovic and J.N. Eckstein focuses on the use of RHEED as a tool for in situ, real-time monitoring of growth processes. The diffraction pattern produced by an electron beam impinging on the growing film at a
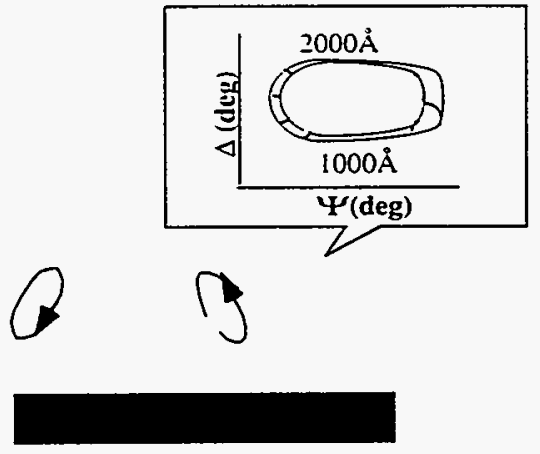

ELLIPSOMETRY

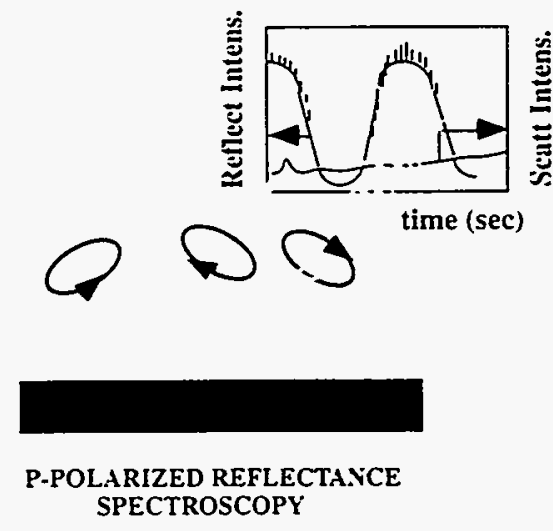

grazing-incidence angle provides a $k$ space view of the crystallography of the film surface (specifically, the lattice constant and the symmetry), its relation to the underlying layers, and the surface roughness on an atomic scale. RHEED can be used in some cases to determine the nature of the chemical reactions at the surface, and is particularly useful for monitoring transient chemical intermediate states which result from the reactions that occur during the growth of each unit cell. 5
The article by T.A. Roberts and K.E. Gray discusses the use of $x$-ray fluorescence spectroscopy (XRFS) for in situ, real-time analysis of film-growth processes. $X$-ray fluorescence induced by $\mathrm{x}$ ray excitation is used to monitor film composition during growth in an ambient background gas. The technique is fairly simple to set up, has a relatively high surface sensitivity, and is nondestructive. $^{\circ}$

The article by N. Dietz and K.J. Bachmann focuses on a new, inexpensive technique for real-time monitoring of epitaxial growth processes based on the reflection of a parallel-polarized light that impinges onto the surface of the substrate close to the Brewster angle of the material. The method can provide information about optical and dielectric properties of the growing film as well as of growth mechanisms.

The experimental methods described in this issue of the MRS Bulletin are not all-inclusive. They present examples of new methods which are being developed or old methods which are being extended to fill the need for better understanding of thin-film growth phenomena in complex multiphase materials and layered heterostructures which utilize these materials for the production of new devices. In addition, the methods were selected on the basis of their potential use as dedicated in situ monitors in production facilities.

\section{References}

1. O. Auciello, A.l. Kingon. D.I. Lichtenwalner, and A.R. Krauss, in Multicomponent ant Multilayered Thin Films for Adianced Wicrotechnologies: Techniques. Funstument.als and Dezices, vol. 234, edited by $O$. Auciello and $J$. Engemann (NATO/ASI Book Series E. Kluwer Academic Publishers, The Vetherlands. 1993) p. 151.

2. B. Doyle, R.T. McGrath, and A.E. Pontau. Vutl. Instrum. Wethois Phys R: 822 , 198, p. $3+4$.

3. A.R. Krauss. Y. Lin. O Auciel's. G I Lamich. D.M. Gruen. I.t. Sihuitz, and R.P.H.

Chang, 1. Viat: 5c: .mel Teches:. A12 + 1004 p. $10+3$.

4. R.K. Sampson, K.A. Conrad. E.A. Irene. and H.Z. Wassoud, I. Electrocinem. Soc. 140 (1993) p. 1.34.

5. J... Eckstein, I. Bozovic, M.E. KlausmeierBrown, G.E. Virshup, and K.S. Ralls, MR: Bulletin XVII (8) (1992) p. 27.

6. T. Roberts and $E$. Grey, in .Halticomponen: and. Wultilavered Thin Films for tudunced .h:crotechnologies: Techniques, Fundament.als ani Devices, rol. 234, edited by $O$. Auciello and $J$. Engemann (NATO/ASI Book Series E, Kluwer Academic Publishers. The Netherlands, 19931 p. 395. 
Orlando tuciello,

Guest Editor tor this issue of the. WRS

Bulletin, is a senior research scientist at the Microelectronics Center of : North Carolina (MCNC) Electronic Technologies Division and is an adjunct protessor in the Department of Mlaterials Science at North Carolina State L'niversity (NCSU). He received MS and PhD degrees trom the Physics Institute "Balseiro," University of Cuyo. Recently, he has focused on coatings for field emitter cathodes. Auciello is a permanent research associate at Argonne National Laboratory and has been a guest scientist at various institutions including Princeton Plasma Physics Laboratory, Argonne, and the University of Wuppertal. His list of publications is extensive, including numerous invited reviews and book chapters, as well as six edited books. He has been the organizer and director of and $a$ lecturer at NATO Advanced Study Institutes. Auciello recentlv received the $1994 \mathrm{R}$. Bunshah Award from the American Vacuum Society, along with Alan R. Krauss and J. Albert Schultz, for the work described in their article appearing in this issue. For more information, Auciello can be reached it $\mathrm{UCV}$ VC, Electronic Technologies Division, 3021 Comwallis Rd.,

Research Triangle Park, ¿C 2,109-2889, phone: +19-2+8-18\%2, tax: ง! $4.7+5-1 \div 55$.

Alan R. Krauss, Guest Euitor for this issue of the . URJ Bulletin, is a stait siientist and group leater in the Materials

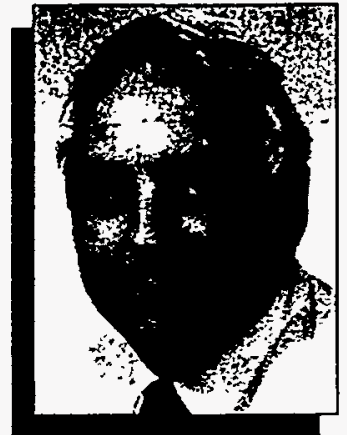

Orlando Auciello

Science and Chemistry

Divisions at Argonne National Laboratory. He received a BS degree in physics from the University of Chicago, and MS and PhD degrees in solid-state physics from Purdue University, followed by a postdoctoral appointment at the University of Chicago. $\mathrm{He}$ recently received the $1994 R$. Bunshah Award from the American Vacuum Society, along with Orlando Auciello and J. Albert Schultz, for the work described in their article appearing in this issue. His research interests include the interaction of energetic particles with solid surfaces, sputtering and ionization phenomena, ion and electron emission from surfaces, thin-film deposition, and alloy segregation phenomena. For more information, Krauss can be contacted at Argonne Vational Laborator: Materials Si:ence and Chemistry Dir:sions, 0,00 5outh Cass Arenue, Argonne. IL ol439, phone: $708-$ בミะ-3520, tax: .08-252 9555, e-mail: alan_ krauss@q̨mgate.anl.go:

Klaus J. Bachmann is a proiessor of materials science and engineering and chemical engineering at . vorth Carolina State Lniversity. He received his degree in chemistry from the Freie Universität Berlin,

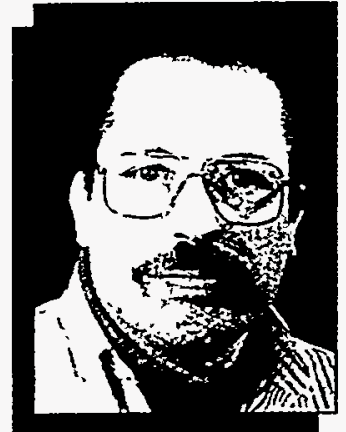

Alan R. Krauss

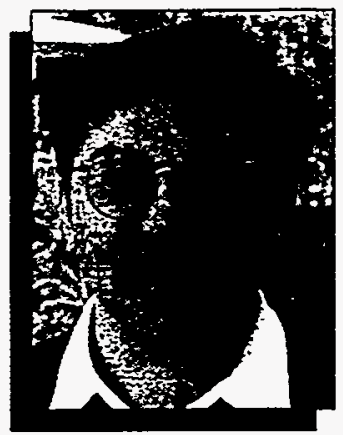

Nikolaus Dietz

working in the field of electrochemical kinetics. In 1970 he joined AT\&T Bell Laboratories where he worked in the Physical Vetallurgy, Solid State Chemistry Research, and Materials Physics Departments on research related to optoelectronics. His present research interests focus on advanced epitaxial methods for nonlinear optical materials and the integration of compound semiconductors with silicon technology uncter conditions of realtime process control.

Iran Bozovic :s a senior si:encis at the Varian Researtin Center, Palo Alto. where he studies sinthesis and properties of sing!e-crystal films and heterostructures that include cuprate superconductors and other complev oxides. Preriousl:; he ivas the head of the Physics Department at the Lniversity of Belyrade, a visiting protessor at Stantord Lniversity and

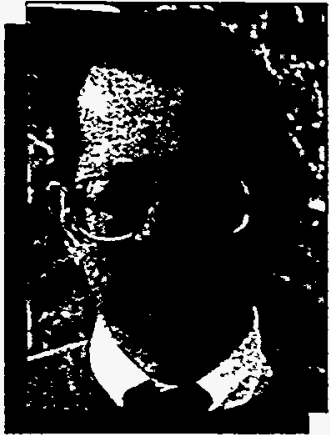

Klaus J. Bachmann

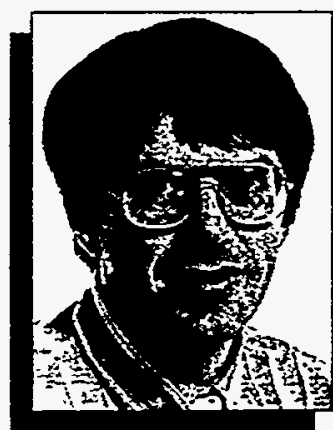

Jim Eckstein

Votre Dame Lniversity in Belgium, and a visiting scholar at the University of CaliforniaBerkelev and the University of Pennsylvania. His credits include over 120 papers, numerous invited talks, four chaired conferences, the Fulbright . Award, and the Belgrade Institute of Physics Prize.

Vikolaus Dietz is a research staif member in the Department of Materials Science and Envineering at . Vorth Carolina State Linversity: He receis ed his PhD derree in prysics from the Technische Universität Berlin. working on optical spectrosicopy and defect characterization in II-IV and chalcopyrte semiconductors. His current research interests are in the areas of thin-riim deposition techniques with real-time control applications. as well as various uptical spectroscopy techniques.

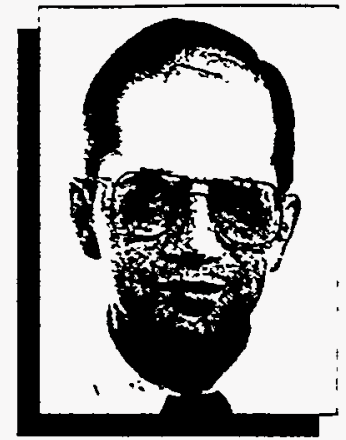

Ivan Bozovic

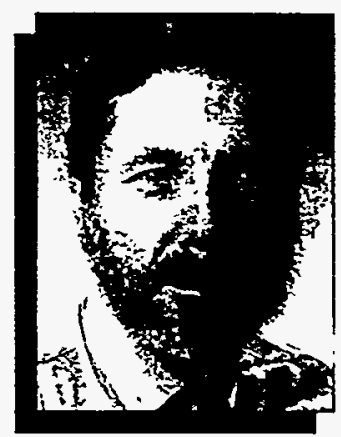

Kenneth E. Gray

Jim Eckstein is a senior scientist at the Varian Research Center, Palo Alto, where he leads the superconductivity group. His interests are in the use of atomic laver-by-laver molecular beam epitaxy of complex oxides, the structuring of artificial materials, and the study of physics at novel heterointerfaces. Eckstein recewed hus PhD degree $n$ phvisics from Staniord Cinic ersity where he researched high-resolutwon !aser spectrosiony and nonlinear cri:cs

Kenneth E. Gray 's a senior si:entst and group eader $n$ the Latertais sclence Division of troonne Vationa. Laborator: He received: his BS and MS degrees in engireering physics trom the Lnuersity of Calirorna-Berkelev: and his PhD degree in phisics trom Cambridge Lniversity: His research interests inclucie zunneing and 

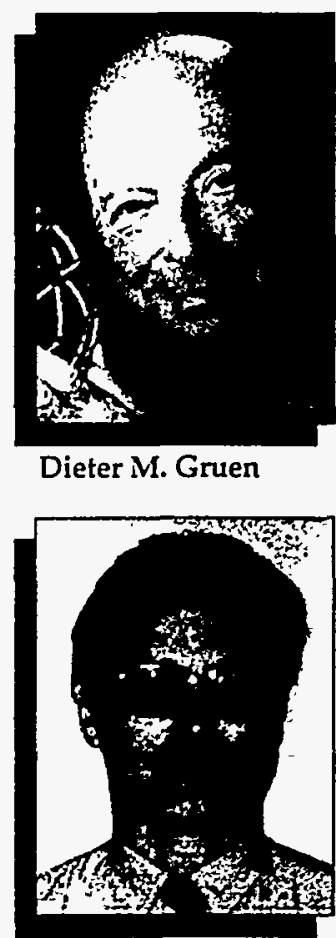

J. Albert Schultz

Hux flow in superconductors and film deposition. His research has resulted in several patents and RD-100 awards. In 1989, he received the Department of Energy Award ior Significant Implication to DOE-Related Technologies in Solid State Phrsics: "ThinFilm Superconducting Device Concepts and Development."

Dieter M. Gruen is a senior sclentist at Argonne Vational Laboratory and associate director of the Materials Sc:ence Division. He receired his BS and .MS jegrees in shemistry at Vorthwestem Linversiit and a PhD degree in themical physics at the University of Chicago. Gruen has received a number of research awards including the American Institute of Chemists Student Mectal, the Department oi Energy . Materials Science Award, the IR-100 Aivard, the Inventor of
Dieter M. Gruen

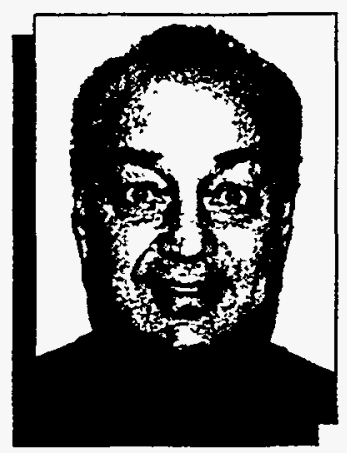

Eugene A. Irene

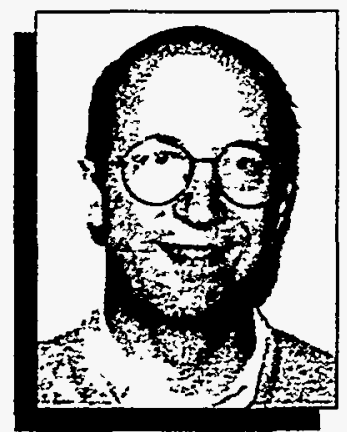

John A. Woollam

the Year from the Patent Law Association of Chicago, and the University of Chicago Award for Distinguished Performance at Argonne. He has published approximately 300 publications.

Eugene A. Irene received a $\mathrm{PhD}$ degree in solid-state chemistry from Rensselaer Polytecinnic Institute in 1972. Since 1982 Irene has held a professorship in physical chemistry at the Lniversity of North Carolina. Irene's ongoing research includes stidies of dielectric riims and semiconductor surtaces and intertaces where a combination of uptical (ellipsometry, reflectance), chemicai IR, XPS, SMIS, etc.), and electronic methods (C-V: I-V, turneling) are used to elucidate filmformation mechanisms anc properties. Irene received the Callinan award of the Electrochemical Society; and has more than 160 pub-

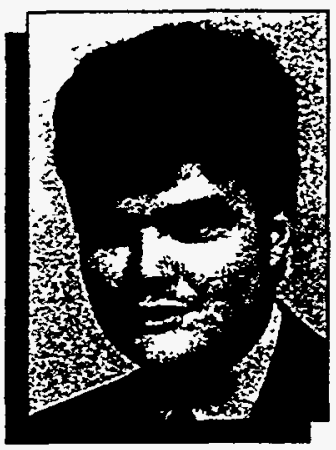

Timothy A. Roberts

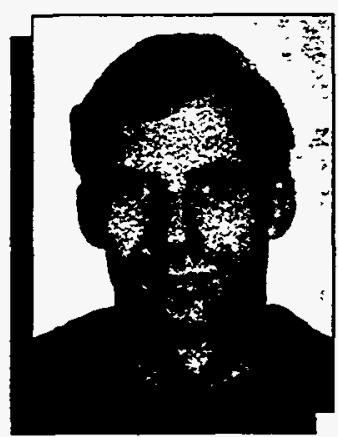

Christopher D. Zuiker

lications in this field. Fifteen $\mathrm{PhD}$ degrees have been awarded thus far in his research group.

Timothy A. Roberts is a research staff member at the Center for Naval Analyses in Alexandria, VA. He received his BS degree in metallurgical engineering and materials science from

Camegie-Mellon University and his PhD in materials science and engineering from Northwestem Lniversitv. His $\mathrm{PhD}$ thesis research was completed in the . Materials Science Dirision at Aggonne National Laawarded a tellowship to participate in the $\mathrm{Na}$ tional Science Foundation Summer Institute in Japan where he was a guest researcher at Sanyo Electric.

\section{J. Albert Schultz re-} ceived a BS degree in chemistry from Southwestern University and an MS degree from the University of North Carolina-Chapel Hill where he also received a $\mathrm{PhD}$ degree in physical chemistry. During the past eight years he has had extensive consultation/collaboration with research groups at IBM, the Space Vacuum Epitaxy Center at the University of Houston,

Naval Research Laboratories, the Department of Energy Mound, Argonne. National Laboratory, Hitachi Central Research Laboratories in Tokyo, and Beer Sheva Nuclear Research Center in Israel. He recently received the $199+$ R. Bunshah Award from the American Vacuum Society, along with Orlando Auciello and Alan R. Krauss, for the work described in their article appearing in this issue.

John A. Woollam is a George Holmes Protessor of Electrical Engineering at the L'niversity of . Vebraska. He re- boratory. In 1992 he was ceived a PhD degree in physics trom . Vichigan State University and was an emplovee of the NASA Lewis Research Center prior to joining the faculty at the Lniversity of North Carolina. His research in recent years has involved the preparation and characterization of thin tilms for application in optics, magnetooptics, multilayer electronics, and environmentally clean surfaces. He has published 300 papers in these areas and is a Fellow of the American Physical Society.

Christopher D. Zuiker received his $B S$ degree in nuclear engineering with highest honors, as well as university honors, from the Lniversity of Illinois-Lrbana. He was awanded a Vational Science Foundation Fellowship and received his PhD degree in astrophysical sciences from Princeton L'niversity with the thesis, "Laser Induced Fluorescence Measurements in an Electron Cyclotron Resonance Plasma Etch Reactor," under the direction of J.L. Cecchi. He is currently working at Argonne .Vational Laboratory in the chemistry and materials science divisions. His research involves plasma-enhanced chemucal vapor deposition of diamond ilms=-

\section{UPCOMING IN NEXT MONTH'S MRS BULLETIN:}

\section{Theme: Organic Thin Films}

Guest Editors: Tisato Kajiyama, Kyushu University; David G. Whitten, University of Rochester; and Toyoki Kunitake, Kyushu University

...including Langmuir-Blodgett films, organic monolayers, lipid bilayers, and other self-assembling structures. 